\title{
EFFECT OF MAGNETIC FIELD IN TREATMENT OF LOWER BACK MYOFASCIAL PAIN SYNDROME: A RANDOMIZED CONTROLLED TRIAL
}

\author{
By \\ El Shiwi AMF \\ Department of Physical Therapy for Musculoskeletal Disorders and its Surgery, \\ Faculty of Physical Therapy, Cairo University.
}

\begin{abstract}
Introduction: Low back pain affects about $60 \%$ to $90 \%$ of the working-age population in modern industrial society. Myofascial pain syndrome is a condition characterized by muscles shortening with increased tone and associated with trigger points that aggravated with activity of daily living. Aim of work: To examine the effects of magnetic field therapy in patients with lower back myofascial pain syndrome. Materials and Methods: Thirty patients were assigned randomly into 2 groups. Subjects in the experimental group $(n=15)$ with main age of 36.73( \pm 2.52$)$ received traditional physical therapy program (infrared radiation, ultrasonic, stretching and strengthening exercises for back muscles) as well as magnetic field, and control group $(\mathrm{n}=15)$ with main age of $37.27 \pm 2.52)$ received traditional physical therapy only. The following parameters including pain severity, functional disability and lumbar range of motion (flexion, extension, right side bending and left side bending) were measured before and after 4 weeks of treatment. Results: The results showed significant improvement in all parameters in experimental group compared with those of control group. Conclusion: On the basis of the present date, it is possible to conclude that a magnetic field is effective as a method of treatment for lower back myofascial pain syndrome patients with the parameters used in the present study.
\end{abstract}

Key words: Magnetic Field, Lower back pain, Myofascial pain Syndrome, Physical therapy. 


\section{Introduction}

Low back pain represents a great variety of conditions that cause inappropriate back function especially in people of working age. It is a major cause of illness and disability, and considered one of the most frequently treated and most costly disease in modern industrial society. (Endean et al., 2011).

The incidence of low back pain ranges between $60 \%$ and $90 \%$ of individuals sometime in their life and is the leading cause of disability in people below the age of 45 years (Nourbaksh and Arab, 2000)

Causes of back ache are numerous: increase sedentary life style, less physical activity among young people and adults, over weight and obesity which contribute to extra stress on the spine, poor postural habits, poor body mechanics in working procedures, certain repetitive motion (Fryomer and Selby, 1991), and myofascial trigger points(Gerwin, 2005).

Myofascial pain is chronic and severe pain charactarized by trigger points in a group of tensed muscles. The mechanisms of developing trigger points include: fatigue, local ischemia, biomechanical bad habits, and sustained muscle overload (Pearce, 2004).

The trigger point restricts motion of the muscle, dcreases circlation, depriving the muscle of nutrients and oxygen resulting in acollection of mtabolic wastes which exciate pain nerve ending and increase muscle spasm and inflammation (Simons, 2002).

Evaluation and treatment of low back pain are still insufficient. Patients still have some degree of disability and pain even after rehabilitation (Difabio et al., 1996)

Magnetic field is the space permeated by the magnetic lines forces surrounding a permanent magnet or coil of wire carry electric current. A magnetic field always exists when there is an electric current flowing. There are three types of magnetic field: a static magnetic field which is fanned in the case of direct current, a time varying magnetic field and pulsed magnetic field. The human body is transparent to the magnetic field, so during application, it acts on all molecules, has non selective action. (Waddas, 1991).

Magnetic field, were applied to promote bone healing, treat osteoarthritis and inflammatory disease of musculoskeletal system, alleviate 
pain and enhance healing of ulcers. This demonstrates how much magnetic field is beneficial for field of physical therapy (Quittan et al., 2000)

\section{Aim of the work:}

To assess the efficacy of magnetic field on pain, functional disability and lumbar range of motion in patients with lower back myofascial pain syndrome.

\section{Materials and Methods}

This study was conducted in the out clinic of Faculty of Physical Therapy,
Cairo University to evaluate the efficacy of magnetic field in treatment of lower back myofascial pain syndrome.

Subjects: Participants were identified and recruited over 8-month period. Forty patients diagnosed clinically with lower back myofascial pain syndrome (according to location of trigger points at lower back muscles and aggravation of pain with back activities) were examined for eligibility in the study (Figure: 1)

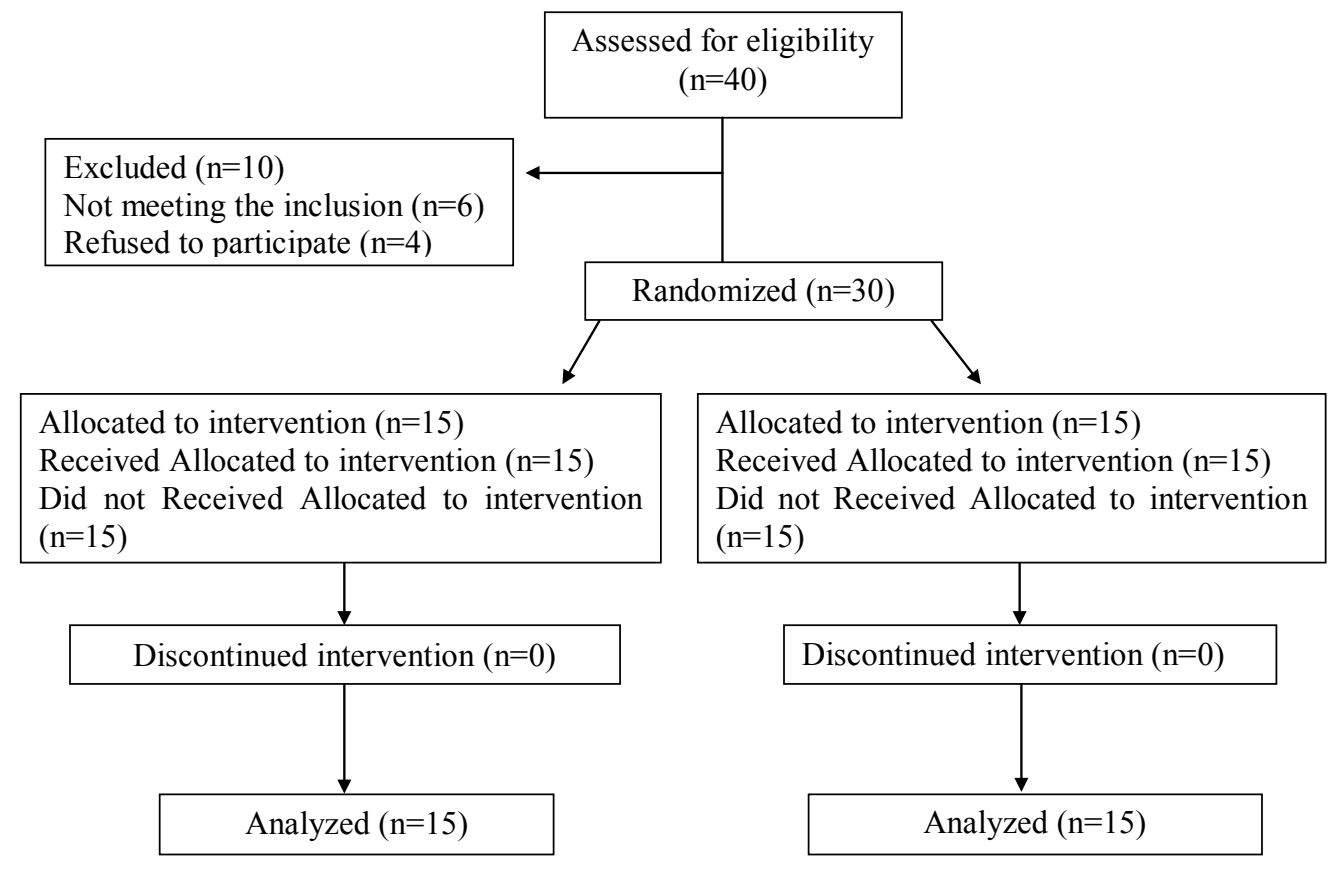

Figure 1: Participant flow diagram 


\section{Inclusion Criteria:}

- Patients (office worker) had low back pain for 3 months ago.

- Patients with active trigger points in lower back muscles.

- $\quad$ Age of the patients ranged from 20 to 40 years.

\section{Exclusion Criteria:}

- Pregnant and lactating women.

- History of previous back surgery.

- Vertebral compression fracture.

- Neurological deficit.

- Current lower extremity symptoms.

- Cardiopulmonary disease with decreased activity tolerance.

The experiment continued with 30 patients (21 female and 9 male), their age ranges from 20 to 40 years signed an informed consent. The subjects were assigned randomly (one by one for each group) into: A (experimental group) 15 patients ( 11 female and 4 male) received (magnetic field and traditional physical therapy program infrared, ultrasonic, stretching exercises and strengthening exercises for back muscles), B (Control) 15 patients( 10 female and 5 male) received traditional physical therapy program only for 12 session over four weeks period.

\section{Instrumentations:}

\section{A- Instrumentations used for evaluation:}

Patients were assessed just before and just after the treatment sessions. The assessment procedures included the following items.

\section{1- Pain assessment:}

Pain assessed by Visual Analog Scale (VAS). VAS is a scale that allows continuous data analysis and uses a $10 \mathrm{~cm}$ line with 0 (no pain) and 10 (worst pain) on the other end .Patients were asked to place a mark a long the line to denote their level of pain (Marc, 2001).

\section{2- Functional disability:}

Functional disability of each patient was assessed by Oswestery disability questionnaire (Appendix II). It is valid and reliable tool. It consists of 10 multiple choice questions for back pain, patient select one sentence out of six that best describe his pain, Higher Scores indicated great pain. [Scores (0-20\%) minimal disability, Scores(20\%- 40\%) moderate, Scores (40\%-60\%) severe, Scores (60\%$80 \%)$ crippled, Scores $(80 \%$ $100 \%$ ) patients are confined to bed] (Fair Bank and Ronald et al., 2000). 
3- Range of Motion (ROM) assessment:

\section{a- Assessment of lumbar flexion}

\section{and extension:}

Modified-Schober flexion technique was used based on the work of Williams et al., 1993. This method is reliable and valid in measuring range of motion of lumbar flexion.

The investigator stood behind the standing patient to identify the posterior superior iliac spines with her or his thumbs, and then an ink mark was drawn along the midline of the lumbar spine horizontal to the posterior superior iliac spines. Another ink mark was made $15 \mathrm{~cm}$ above the original mark; the distance between superior and inferior skin marks was measured. Then the investigator instructed the patient to bend forward into full lumbar flexion and the new distance between superior and inferior skin marks was measured.

Then the investigator instructed the patient to bend backward into full extension and the new distance between superior and inferior skin marks was measured as a straight line. The change in the normal difference between marks was used to indicate the amount of lumbar extension .This test was performed for three consecutive times and the mean value was considered as lumbar extension range of motion

\section{b- Lateral flexion:}

Lateral flexion was measured as the distance from the tip of the index finger to the floor at maximal comfortable lateral flexion based on the work of Ponte et al. (1984). The subject was instructed to move as far as possible into lateral flexion. This test was performed for three consecutive times for each side and the mean value for each side was considered as the lateral flexion range of motion.

\section{B- Instrumentation used for treatment:}

\section{ASA Magnetic field (Automatic PMT Quattro pro):}

ASA magnetic field is a device for magneto-therapy, its model is (Automatic PMT Quattro pro) and its serial number is (00001543). It consists of an appliance, motorized bed and solenoids. The appliance must be connected to electrical mains supplying $230 \mathrm{v} \pm 10 \%$ at a frequency of 50 or 60 $\mathrm{Hz}$ with earth connection. The intensity and spatial lay out of the generated magnetic field depend on the type of solenoid used. 


\section{Infrared radiation:}

Infrared has been used as a form of heat for many purposes. Its model is $4004 / 2 \mathrm{~N}$. The device has a power of $400 \mathrm{w}$, voltage $203 \mathrm{v}$ and frequency of $50 / 60 \mathrm{~Hz}$. Infrared is sometimes chosen as a form of heat prior to stretching, mobilization, traction, massage and exercise therapy.

\section{Ultrasonic device:}

Ultrasonic device Phyaction 190 serial number $2745,230 \mathrm{~V}, 300 \mathrm{~mA} / 50$ - $60 \mathrm{~Hz}$, Pus: $8 \mathrm{w}$. It is used for pain relief and break down of adhesions in the case of low back pain (LBP).

\section{Treatment procedure:}

\section{A- Experimental Group:}

This group was consisted of 15 patients. They had received:

Infrared radiation for 20 minutes/ session at distance of $60 \mathrm{~cm}$ from lumbar region, while patients in prone lying position for 12 sessions 3/week every other day for one month (Shabana et al., 2001).

Ultra sonic: for 5 minutes, $1 \mathrm{~Hz}$, continuous mode of application $1.5 \mathrm{w} /$ cm2 (Brain et al., 2000).

Mild stretching exercises for 30 seconds for hamstring, calf muscles, and back muscles from long setting (El Naggar et al., 1991).

Strengthening exercises for back muscles (bridging and active back extension) (Jari, 2004)). Each exercise was down 3 times at session with hold for 6 seconds.

Pulsed Electromagnetic Field, frequency $10 \mathrm{~Hz}$, intensity of 20 gauss and duration of $15 \mathrm{~min}$. (Trock et al. 1993). While patients in prone lying position expose lumbar to (PEMF), 3 sessions per week every other day for one month.

\section{B- Control Group:}

This group was composed of 15 patients. They had received traditional therapy program.

\section{Statistical analysis}

Data obtained from the study was coded and entered using the statistical package SSPS. Descriptive statistics for demographic data and all out come measures were expressed as mean and standard deviation Comparisons between groups were done using unpaired t- test. Comparisons within groups were done using paired t- test. $P$ values less than 0.05 and 0.01 were considered statistically significant. 


\section{Results}

A total of 30 patients participated in this study, they were assigned randomly into two groups; the control group which consisted of 15 patients with mean age of $37.27( \pm 2.52)$ years, mean weight of 72.73 $( \pm 8.66) \mathrm{kg}$, mean height of $164.27( \pm 8.71) \mathrm{cm}$, mean duration of illness of $7.53( \pm$ $3.27)$ months, and mean number of sessions of $11.35( \pm .83)$.

Table 1- Demographic data of patients.

\begin{tabular}{|l|c|c|c|c|}
\hline \multicolumn{1}{|c|}{ Variables } & $\begin{array}{c}\text { Control } \\
\text { group }\end{array}$ & $\begin{array}{c}\text { Experimental } \\
\text { group }\end{array}$ & t-test & P-values \\
\hline Age (year) & $37.27 \pm 2.52$ & $36.73 \pm 2.52$ & .473 & .80 (N.S.) \\
\hline Weight $(\mathbf{K g})$ & $72.73 \pm 8.66$ & $77.4 \pm 10.23$ & 1.349 & 4.67 (N.S.) \\
\hline Height $(\mathbf{C m})$ & $164.27 \pm 8.71$ & $162.2 \pm 9.73$ & .613 & 2.07 (N.S.) \\
\hline Duration of illness (month) & $7.53 \pm 3.27$ & $8.0 \pm 2.93$ & .412 & .47 (N.S.) \\
\hline Number of sessions & $11.35 \pm .83$ & $11.66 \pm .81$ & .421 & .67 (N.S.) \\
\hline
\end{tabular}

N.S.: Non Significant

The experimental group consisted of 15 patients with a mean age of 36.73 $( \pm 2.52)$ years, mean weight of $77.4( \pm 10.23) \mathrm{Kg}$, mean height of $162.2( \pm 9.73) \mathrm{cm}$, mean duration of illness of $8.6( \pm 2.93)$ months, and mean number of sessions of $11.66( \pm .81)$. Using unpaired t-test showed that there were no significant differences between groups before treatment for these demographic data (Table 1). 
Table 2- Comparison between groups before treatment.

\begin{tabular}{|l|c|c|c|c|}
\hline \multicolumn{1}{|c|}{ Variables } & Control group & $\begin{array}{c}\text { Experimental } \\
\text { group }\end{array}$ & T & P-values \\
\hline Pain Severity & $7.66 \pm 8.23$ & $8.05 \pm 7.93$ & 1.311 & .20 (N.S.) \\
\hline Function disability & $48.73 \pm 2.03$ & $50.67 \pm 1.32$ & .797 & .43 (N.S.) \\
\hline Flexion & $3.20 \pm .67$ & $3.23 \pm .77$ & .125 & .90 (N.S.) \\
\hline Extension & $1.53 \pm .51$ & $1.36 \pm .44$ & .950 & .35 (N.S.) \\
\hline Right side bending & $67.8 \pm 2.96$ & $68.53 \pm 3.89$ & .581 & .56 (N.S.) \\
\hline Left side bending & $66.93 \pm 3.10$ & $69.47 \pm 4.02$ & 1.93 & .06 (N.S.) \\
\hline
\end{tabular}

N.S.: Non significant

Unpaired t-test was used to detect differences between groups before treatment. There was no significant differences between groups regarding pain severity $(\mathrm{t}=$ 1.311 , $\mathrm{p}-0.20)$, functional disability $(\mathrm{t}=0.797, \mathrm{P}=0.43)$, lumbar flexion $(\mathrm{t}=0.125$, $\mathrm{p}=0.90)$, lumbar extension $(\mathrm{t}=0.950, \mathrm{P}=0.35)$, lumbar right bending $(\mathrm{t}=0.581, \mathrm{p}=$ $0.56)$, and lumbar left bending $(\mathrm{t}=1.93, \mathrm{p}=0.06)$ (Table 2).

Table 3- Post treatment inter group difference:

\begin{tabular}{|l|c|c|c|c|}
\hline \multicolumn{1}{|c|}{ Variables } & Control group & $\begin{array}{c}\text { Experimental } \\
\text { group }\end{array}$ & $\mathbf{T}$ & P-values \\
\hline Pain Severity & $41.133 \pm 12.56$ & $52.4 \pm 7.51$ & 2.981 & $.006^{* *}$ \\
\hline Function disability & $29.33 \pm 7.92$ & $35.53 \pm 4.59$ & 2.621 & $.014^{* *}$ \\
\hline Flexion & $4.80 \pm 1.85$ & $6.1 \pm 1.49$ & 2.113 & $.044^{*}$ \\
\hline Extension & $1.96 \pm 693$ & $2.83 \pm 1.04$ & 2.674 & $.012^{* *}$ \\
\hline Right side bending & $17.40 \pm 4.15$ & $24.87 \pm 3.98$ & 5.027 & $.0001^{* *}$ \\
\hline Left side bending & $17.87 \pm 3.60$ & $25.73 \pm 3.82$ & 5.797 & $.0001^{* *}$ \\
\hline
\end{tabular}


Unpaired t-test was used to detect differences between groups after treatment. There was significant difference in favor of experimental group than control group of: pain severity, functional disability, lumbar flexion, lumbar extension, lumbar right bending and lumbar lift bending (Table 3).

\section{Discussion}

Lower back myofascial pain syndrome is one of the most common causes of inappropriate back function. Magnetic therapy has been reported to be effective in the treatment of patients with back pain. This study was conducted to examine the effects of magnetic field (Frequency of $10 \mathrm{~Hz}$, intensity of 20 Gauss and duration for 15 minutes precession, three sessions per week for successive 12 weeks) on improvement of pain, functional disability and back range of motion in chronic mechanical low back pain patients.

All patients in both groups had symptoms of low back pain. This aggress with Morki and Sinaki (1993) who reported that low back pain generally is marked by pain increasing during activity such as bending, twisting, lifting, prolonged sitting and standing.
They also had decrease of functional ability and back range of motion due to pain and muscle spasm and this agree with ( Jari et al., 2004)

\section{A. Traditional physical therapy program (G1)}

\section{Pain severity:}

From statistical analysis of pre and post values of pain assessment in the control group, there was a decrease in back pain at the end of treatment rather than pretreatment values and this difference was significant. Pain reduction may be due traditional physical therapy and may be attributed to: The effect of infrared which has been used as a form of heat for pain relief, and reduction of muscle spasm. Also increase in sensory responses via an increase in endorphins, which could affect the pain gate mechanism (Kitchen and Partridge, 1991). Heat application had been proven to be effective in relieving pain, reducing muscle spasm and disability in acute and chronic LBP (Nadler et al., 2003).

Ultrasonic increases the threshold of pressure produced by pain receptors. The conduction velocity of large diameter nerve fibers (A beta) increased after application of ultrasonic while the 
conduction velocity of small diameter nerve fibers (A delta fibers) that are responsible for pain decreased (Draper et al., 1995).

It causes a significant tissue heat that alters the viscolestic properties of connective tissue making it move extensible (Barian et al., 2000).

Khalil et al., (1992) showed that stretching exercises for back muscles and hamstrings helped in reducing pain and improving flexibility of low back pain patients.

\section{Functional disability:}

Concerning functional disability there was significant decrease of functional disability post treatment of the traditional program group. O'Sullivan et al., (1997) used oswestry disability questionnaire to assess patient's level of functional disability, they report decrease in functional disability.

Myoelectric activity level increased after strengthening exercises reflects improve function of neuro muscular system because individual is capable of voluntarily recruiting move motor neuron and increasing their firing rate (Khalil et al., 1992).

This finding also, has been supported by Johanssen et al., (1995) who found that dynamic exercises for back and abdomen with stretching exercises was effective in reducing functional disability. Improve multifidus muscle strength (which atrophy in low back) pain improve functions (Hides et al., 1994).

\section{Range of motion (ROM):}

Regarding the range of motion of lumbar flexion, extension, right side bending and left side bending, from the statistical analysis of pre and post values there was a significant increase in lumbar range of motion (flexion, extension, Rt side bending and Lt side bending) at traditional physical therapy program group. This finding supported by Magnsson et al. (1998) who found that functional ability and range of motion of lumbar flexion, extension, lateral right bending and lateral left bending improved after physical therapy program included strength and flexibility exercises because of increase muscle strength, reduction of pain, improve muscle flexibility and improve motor control skills.

Improved range of motion has been associated with symptoms relief in patients with chronic back problem after flexibility program supporting the finding of Battie et al., (1990). 
Jari et al., (2004) reported that increased trunk flexion range of motion after flexion and extension exercises due to increased flexibility and mobility of the trunk. Improvement of patients physical activities, psychological status and relief of pain responsible for decrease disability and increase range of motion this was supported by (Sullivan et al., 2000).

\section{B. Magnetic field group (G2):}

\section{Pain severity:}

To examine the analgesic effects of Pulsed Electro Magnetic Field (PEMF), comparison between pre and post results of pain assessment using visual analogue scale for the patients in the experimental group was done. The results showed a highly significant decrease in low back pain at the end of treatment program. These results come in agreement with Trock et al., (1993), Segal et al., (1999), Jacobson et al., 2001, Hinman, (2002) that revealed significant pain relief due to application of PEMF, for patients with low back pain.

The analgesic effect of pulsed electromagnetic field therapy could be attributed to one of the following mechanisms: First, the physiologic mechanisms of pain relief due to application of magnetic field may be due to presynaptic inhibition or decreased excitability of pain fibers (Hinman, 2002).Other postulated that magnetic field influences the small C-fibers (Weintraub, 1999). The authors, also, found that exposure to magnetic field produce a reversible blockade of sodium-dependent action potential firing and calcium dependent response to the irritant.

Second, the molecular mechanism of the effect of magnetic field may involve conformational changes in the ion channels or neuronal membrane. Considering the time required for the effect on action potentials, multiple mechanisms must be acting simultaneously, possible including indirect effect such as reduction in activity of channel posphorylating enzymes (Segal, 1999).

Third, evidence exists that pulsed electromagnetic field can modulate the actions of hormones, antibodies and neurotransmitters surface receptor sites of a variety of cell types (Adey, 1989).

\section{Functional disability:}

To examine the effect of the (PEMF) on reducing functional disability, 
comparison between pre and post results of functional disability using oswestry disability questionnaire fore the patients of experimental group there was significant decease in functional disability at the end of the treatment.

These result are consistent with Jacobson et al., (2001) who stated that the effect of magnetic field extend to the structures in the higher levels such as connective tissue, muscle and organs, thus producing less inflammation, improve circulation, diminution of pain and hence improve function. Bassett et al., (1982) report that PMF was used to reduce edema and improve microcirculation, possibly by facilitating water reposition, inhibit inflammation, accelerates hematoma resolution and enhance microcirculation. Weinberger et al., (1996) reported that synovitis and inflammatory process are significantly suppressed by application of magnetic field.

The improvement in functional ability for patients in this study could be attributed to the positive antiinflammatory and analgesic effect of magnetic filed which lead to decease pain and inflammation and improve back functions.

\section{Range of motion (ROM):}

Concerning lumbar range at motion, there was significant increase at lumbar (flexion, extension, Rt side bending and Lt side bending after treatment at patients by magnetic field.

These results come in agreement with Hinman (2002), who reported that application of magnetic field to the musculoskeletal problem can reduce pain, inflammation and enhance movement.

Pulsed electromagnetic field is useful in reducing pain and relief of muscle spasm, so improves patient functions and trunk range of motions in chronic mechanical low back pain patients (Holcomb et al., 1991)

Magnetic field decreases joint and muscle pain, decreases joint swelling and stiffness and improve soft tissue repair so increase mobility and a quality of life (Van Nguen et al., 2002).

The improvement in trunk range of motion in patients in this study could be attributed to the positive analgesic effect, anti inflammatory effect and reduction at muscle spasm so improve lumbar mobility and range of motion. (Trock et al., 1993) 
From all of the above, it was approved that application of magnetic field is effective as a treating method for patients with lower back myofascial pain syndrome owing to its analgesic and anti-inflammatory effects so it helps in reducing pain and functional disability and improving lumbar range of motion. No side effects of magnetic field have been en reported in literature (Rubin et al., 1993).

\section{Conclusion}

On the basis of the present data, it is possible to conclude that magnetic filed therapy is effective with traditional physical therapy program in reducing pain, functional disability and improving lumbar range of motion in patients with lower back myofascial pain syndrome.

\section{References}

1. Adey WR (1989): Physiological signaling across cell membranes and cooperative influences of extremely low frequency electromagnetic fields. In: Frohlich H, ed. Biological Choherence and Response to External Stimuli. New York, NY: Springer-Verlag.

2. Barian V, Ashikage T, Bradan C F and Nancy JZ (2000): The effect of ultrasound and stretch on Knee ligament Extensibility JOSPT, 30; (6): 341-347.

3. Bassett CAL, Mitchell SN, Gaston SR (1982): Pulsing electromagnetic field treatment in ununited fractures and failed arthrodeses. J. Am. Med Assoc; 247: 623.
4. Battie MC, Biogs SJ, Fisher LD, Spengler DM and Hansson TH (1990): The role of flexibility in back pain complaints with in industry. A prospective study. Spine; 15(8): 768-774.

5. Brain V, Ashikage T, Braden CF and Nancy JZ (2000): The effect of ultrasound and stretch on knee ligament Extensibility. JOSPT; 30 (6): 341-347.

6. Difabio RP, Mackey G and Holte JB (1996): Physical therapy outcomes for patients receiving worker's compensation following treatment for herniated lumbar disc and mechanical back pain syndrome. JOSPT; 23 (3): 180-187.

7. Draper D, Schulthies S, Sorrito P and Hautala A (1995): Temperature changes in deep muscles of humans during ice and ultrasound study. JOSPT; 21: 151-157.

8. El Naggar IM, Nardin M, Sheikhzaden A, Parnianpour M, Kahanovitra N (1991): Effects of spinal flexion and extension exercises on low back pain and spinal mobility in chronic mechanical low back pain patients. Spine; 16: 967-972.

9. Endean A, Palmar K and Coggon D (2011): Potential of MRI finding to reline case definition for mechanical low back pain in epidemiological studies. A systemic review. Spine; 36(2):160-169.

10. Gerwin RD (2005): A review of myofascial pain fibromylagia factor that promote their persistence .Acupuncture in medicine; 32(3):121-145.

11. Hides JA, Stroke MJ, Saide M, Jull GA and Cooper DH (1994): Evidence of lumbar multifidus muscle wasting ipsilateral to symptoms in patients with acute/sub acute low back pain. Spine; 19(2): 165-172.

12. Hinman MR; Ford J and Heyl H (2002): Effects of Static magnets on chronic Knee Pain and Physical Function a double-blind study. AltemTher-Health-Med; 8 (4):50-5. 
13. Holcomb RR, Parker RA, Harrison MS (1991): Biomagnetics in the treatment of human painpast, present, future. Environ Med; 8:24-30.

14. Jacobson J, Gorman RY. Amanasbin W, Saxena B and Clayton L (2001): Low amplitude extremely low frequency magnetic field for the treatment of osteoarthritic knee, a double blind clinical study. Atern ther health med; 7(5): 54-69.

15. Jari PA, Taru V, Markkuk and ölavi A (2004): Activation at lumbar paraspinal and abdominal muscles during therapeutic exercises in chronic low back pain patients. Arch of Phy. Med. and Rehab; 85 (5): 823 - 823.

16. Johannson F, Remvig L, Kryger P, Back P and Warming S (1995): Exercises for chronic low back pain: a clinical trial. JOSPT; 22 (2): 52-59.

17. Khalil TM, A sfour S, Martiner L, Maly S and Rosomff H (1992): Stretching in the rehabilitation of low back pain patients. Spine; 17 (3): 311-322.

18. Kitchen S and Partidge C (1998): Infrared therapy. Physiotherapy; 77 (2): 93-100.

19. Magnusson ML, Bishop JB, Hasselquist L, Spratt K and Fond Pope MH (1998): Range of motion and motion pattern in patients with low back pain before and after rehabilitation. Spine; (23): 2631- 2639.

20. Marc A (2001): Pain measurement, in P. Prithvi Ray: pain medicine a comprehensive review, Mosby, Los Angeles, California, USA, pp. 3637.

21. Morki B and Sinaki M (1993): Painful disorders of the spine and back pain syndromes. In sianki M: Basic clinical rehabilitation medicine, 2nd ed. St. Louis, Mosby- year book, pp. 489-502.

22. Nadler SF, Steiner DJ, Detty SR, Erasala GN, Henge hold DA, Weig and KW(2003): Over height use of continuous low level heat wrap therapy for relief of low back pain Arch Phys Med Rehabil; 84 (3): 335-342.
23. Nourbakhsh MR, Arab AM (2002): Relationship between mechanical factor sand incidences of low back pain. J Orthop Sports Phys Ther; 32:447-460.

24. O’Sullivan PB, Mampphyty D, Tweny CT, Allison GT (1997): Evaluation of specific stabilizing exercise in the treatment of chronic low back pain with radiological diagnosis of spondylolysis or spondylolisthesis. Spine; 22(24): 2959-2967.

25. Pearce JM (2004): Myofascial pain fibromyalgia or fibrosities? Eur Neural; 52: 67-72.

26. Ponte DJ, Jensen GT, Kent BE (1984): A preliminary report on the use of McKenzie protocol versus Williams's protocol in the treatment of low back pain JOSPT; 6(2): 130139.

27. Quittan M, Schuhfried O, Wiesinberg G and Moser V (2000): Clinical effectiveness of magnetic field therapy. A review of literature Acta med Austriaca; 27(3): 61-68.

28. Rubin CT, Danahue HJ, Rubin JE and Mc leod KT (1993): Optimism of electric field parameters for control of bone remolding. Journal of bone and mineral research; 8: 573- 581.

29. Segal N, Huston J, Fuchs H, Halcomb R and Mclean M (1999): Efficacy of static magnetic device against knee pain associated with inflammatory arthritis. J Clinical Rheumatol; 5: 302-304.

30. Shabana AA, Mahsen MA, Senna MK, and Steen M (2001): Lumbar discherrinations: MRI and clinical follow-up in patients treated with traction. The Egyptian Rheunatologist; 23: 197209.

31. Simons DG (2002): Understanding effective treatment of myofascial trigger points. Journal of body work and movement therapies; 6(2)8188 . 
32. Sullivan MS, Saraf LD and Riddle DL (2000): The relationship of lumbar flexion to disability in patients with low back pain. Physical therapy; 80 (3): 240- 250.

33. Trock D, Bollet A, Duer R, Fielding L, Miner W, Markell R (1993): A double-blind trial of the clinical effects of pulsed electromagnetic fields in osteoarthrosis J. Rheumatol; 20(3): 456-460.

34. Van Nguen J and Marks R (2002): Pulsed electromagnetic fields for treating osteoarthritis. Physiotherapy; 88 (8): 458- 470.

35. Waddas RS (1991): Biomagnetism. Ellis Horwar Series in Physics and Application,
PWN Polish, Scientific Publishers, Warsaw, Printed in Poland.

36. Weintraub MI (1999): Magnetic fields, environmental health criteria. World Health Organization; Geneva.

37. William R, Binkley J, Bloch R, Goldsmith CH and Minuk T (1993): Reliability of the modified schober and double inclinometer methods of measuring lumber flexion and extension. Physical therapy; 73 (1): 26-37.

38. Winberger A, Nyska A and Giler S (1996): Treatment of experimental inflammatory sinovitis with continuous magnetic field. Ist $\mathrm{J}$ Med Sci; 32: 1197-201. 